\title{
Coblation versus Traditional Tonsillectomy: A Double Blind Randomized Controlled Trial
}

\author{
Zaki Mohammed Farouk* \\ Department of Otorhinolaryngology, Qena University Hospital, South Valley University, Egypt
}

Submission: March 30, 2017; Published: April 11, 2017

*Corresponding author: Zaki Mohammed Farouk, Department of Otorhinolaryngology, Qena University Hospital, South Valley University, Egypt

\begin{abstract}
Background: Coblation tonsillectomy is a recently introduced surgical technique. To measure its benefits against traditional tonsillectomy techniques regarding their advantages and complications.
\end{abstract}

Aim of work: The study aims to identify differences in time consumption during operation, amount of lost blood during operation, immediate postoperative pain, postoperative haemorrhage whether primary or secondary and time needed to return back to the normal activity and diet.

Study Design: Prospective observational cohort study.

Methods: Comparing 507 coblation tonsillectomies with a control group of 497 traditional tonsillectomies performed by blunt dissection regarding time consumption during operation, amount of lost blood during operation, immediate postoperative pain, postoperative haemorrhage whether primary or secondary and time needed to return back to the normal activity and diet. Each patient had preoperative blood investigations regarding haemoglobin concentration, prothrombin time \& concentration to exclude any coagulation disorder. postoperative analgesics and broad spectrum antibiotics were administered by all patients.

Results: Mean operation time was $10.63 \pm 2.45$ minutes in coblation group and $30.66 \pm 8.66$ minutes in traditional group. The mean operation time was thus significantly less for coblation group $(\mathrm{p}<0.000)$. Intraoperative blood loss turned out to be $65.06 \pm 8.73 \mathrm{ml}$ for the coblation and $174.31 \pm 43.98$ for the traditional group $(\mathrm{p}<0.000)$. Mean return to normal diet period was significantly shorter in the coblation group ( $5.00 \pm 1.41$ vs. $9.95 \pm 1.98$ days) $(\mathrm{p}<0.000)$. Otherwise, return to normal behavior was earlier in the coblation group $(10.30 \pm 2.80$ vs. $13.59 \pm 3.74$ days) $(\mathrm{p}<0.000)$. Postoperative primary hemorrhage rate was higher in traditional group $(0.8 \%)$ than coblation group $(0.2 \%)$. However, secondary hemorrhage rate was higher in coblation group (1.2\%) than traditional group $(0.2 \%)$.

Conclusion: In this study, the new technique using tissue coblation for tonsil dissection offers significant advantages in the operation time compared with dissection tonsillectomy. Coblation is associated with early return to daily activities. Coblation tonsillectomy was associated with a higher incidence of secondary hemorrhage.

Keywords: Coblation tonsillectomy; Traditional tonsillectomy

\section{Introduction}

Tonsillectomy is the most routinely performed surgical operation in the recent years. There have been lots of controversies about tonsillectomy techniques to provide better conditions with more benefits and less complications [1]. For more than a century, traditional dissection tonsillectomy has remained the gold standard for tonsil removal [2]. Traditional tonsillectomy leaves the wound open to heal by secondary intention, thus causes pain and bleeding as two major postoperative complications. This is the reason pioneers usually concentrate to decrease these two problems with comparing various techniques [3]. Considering the mentioned morbidities, attempts have been made to improve the outcome by developing new techniques with less postoperative pain and short recovery period. Available techniques include cold-knife dissection, guillotine excision, electrocautery, cryosurgery, the harmonic scalpel, laser tonsillectomy, bipolar diathermy dissection, radiofrequency and coblation methods [4].

Coblation (Controlled ablation), pronounced as plasma technology was recently used in tonsillectomy as it is minimally invasive and low thermal technique. When current from radiofrequency probe pass through saline medium it breaks saline into sodium and chloride ions. These highly energized 
ions form a plasma field which is sufficiently strong to break organic molecular bonds within soft tissue causing its dissolution [5]. Coblation tonsillectomy was initially introduced in 2001 following which a great amount of articles have been published either to confirm its efficacy or to reject that because of unsatisfactory or unproven outcomes with undesirable costeffectiveness [6,7]. However, more studies are still required to reveal a clear conclusion. Even though some former studies showed a reduced postsurgical pain and no significant morbidities like postoperative hemorrhage, they have not been considered due to their small sample size. Quick return to normal diet was also reported $[8,9]$. A study observed healing process of the tonsillar bed in 10 patients and concluded that coblation method would be more preferable than bipolar dissection [10]. A recent study defended use of coblation surgery because of decreased bleeding and pain, but cases in the study were only 14 patients [11].

Another study in the UK found no benefits for coblation method comparing with conventional tonsillectomy, indicating that traditional tonsillectomy is superior to coblation method. The NICE guidelines have suggested that coblation is probably associated with decreased postoperative pain comparing with bipolar diathermy, however, the outcomes may be different for that of the monopolar diathermy or cold dissection [12]. This study compares coblation and traditional tonsillectomy techniques regarding their advantages and complications.

\section{Materials and Method}

A prospective double-blind randomized controlled trial, we tried to find out whether coblation technique decreases the postoperative morbidity compared to traditional dissection tonsillectomy. The study was recruited between 2012 and 2015, comparing 507 coblation tonsillectomies with a control group of 497 traditional tonsillectomies performed by blunt dissection regarding time consumption during operation, amount of lost blood during operation, immediate postoperative pain, postoperative haemorrhage whether primary or secondary and time needed to return back to the normal activity and diet were compared between two groups. Each patient had preoperative blood investigations regarding haemoglobin concentration, prothrombin time \& concentration to exclude any coagulation disorder. All tonsillectomies were performed under general anaesthesia using standardized anaesthetic technique.

All patients were fasted for 6-8 h before anesthesia. After inserting intravenous line, lactated Ringer's solution was started and monitors (noninvasive blood pressure, ECG, and pulse oximeter for Sp02) were used. Patients received a standardized anesthetic technique that included induction with propofol (2-3 $\mathrm{mg} / \mathrm{kg}$ intravenously), and atracurium ( $0.5 \mathrm{mg} / \mathrm{kg}$ intravenously) to facilitate endotracheal intubation with suitable sized cuffed tube. Fentanyl (1-2 $\mu \mathrm{g} / \mathrm{kg}$ ) was administered as an analgesic agent before infiltration. Anesthesia was maintained with isoflurane in oxygen/air mixture. Patients were mechanically ventilated in ventilation parameter that maintained an endtidal carbon dioxide (EtCO2) around 30-35 mmHg. After endotracheal intubation, positioning and application of mouth gag. Randomization occurred in theatre once the patients were anaesthetized allocated them to the coblation group or the cold dissection control group. Tosillectomies were performed by the same ENT surgeon.

At the end of the surgery, anesthesia was discontinued, and the residual effect of muscle relaxant was reversed with neostigmine $(0.04 \mathrm{mg} / \mathrm{kg})$ and atropine $(0.02 \mathrm{mg} / \mathrm{kg})$. The tracheal tube was removed in the lateral position and then oxygen was administered through a face mask to the patient. After extubation, patients were shifted to the recovery room. Postoperative analgesics and broad spectrum antibiotics were administered by all patients. Operation time, from insertion till removal of mouth gag, was recorded for each case, and recorded intraoperative blood loss by checking volume of blood in suction bottle after the operation. Data including volume of blood loss, operation time, postoperative hemorrhage, days needed to return to work and normal diet were gathered in both groups. Patients were examined for the following postoperative complications during postsurgical visits: primary hemorrhage, secondary hemorrhage, and readmission. On discharge, the patients were advised to call the medical group for any complications especially bleeding.

The primary hemorrhage was defined as bleeding occurring within 24 hours after surgery and secondary hemorrhage as bleeding after 24 hours postoperatively. Each of patients completed a questionnaire concerning the time to return to normal activity. Data were entered into a database and analyzed using SPSS software (SPSS, Windows, version 16). Chi-squared tests were used to compare graded scores for pain. Data of day of return to work and normal diet were analyzed using student's t-test.

\section{Results}

There was no significant difference between the mean age of two groups ( $p>0.05)$. Intraoperative blood loss turned out to be $65.06 \pm 8.73 \mathrm{ml}$ for the coblation and $174.31 \pm 43.98$ for the traditional group $(\mathrm{p}<0.000)$. Mean operation time was $10.63 \pm 2.45$ minutes in coblation group and $30.66 \pm 8.66$ minutes in traditional group. The mean operation time was thus significantly less for coblation group $(\mathrm{p}<0.000)$. Mean return to normal diet period was significantly shorter in the coblation group $(5.00 \pm 1.41$ vs. $9.95 \pm 1.98$ days $)(p<0.000)$. Otherwise, return to normal behavior was earlier in the coblation group $(10.30 \pm 2.80$ vs. $13.59 \pm 3.74$ days $)(p<0.000)$ as shown in (Table 1). Furthermore, it was revealed that postoperative primary hemorrhage rate was higher in traditional group. However, secondary hemorrhage rate was higher in coblation group than traditional group (Table 2). During follow up period, no other major or minor complications occurred in our study. 


\section{Global Journal of Otolaryngology}

Table 1: Operation time, blood loss and Postoperative diet intake and regaining the normal behavior of patients.

\begin{tabular}{|c|c|c|c|}
\hline \multirow{2}{*}{ Parameter } & Coblation & \multicolumn{1}{|c|}{ Traditional } & \multirow{2}{*}{ P-Value } \\
\cline { 2 - 3 } & \multicolumn{2}{|c|}{ Mean \pm SD } & 0.000 \\
\hline $\begin{array}{c}\text { Operation } \\
\text { Time } \backslash \text { min }\end{array}$ & $10.63 \pm 2.45$ & $30.66 \pm 8.66$ & 0.000 \\
\hline Blood Loss $\backslash \mathrm{ml}$ & $65.06 \pm 8.73$ & $174.31 \pm 43.98$ & 0.000 \\
\hline $\begin{array}{c}\text { post-operative } \\
\text { diet intake } \\
\text { days }\end{array}$ & $5.00 \pm 1.41$ & $9.95 \pm 1.98$ & 0.000 \\
\hline $\begin{array}{c}\text { Return to } \\
\text { normal } \\
\text { Behavior } \backslash \text { day }\end{array}$ & $10.30 \pm 2.80$ & $13.59 \pm 3.74$ & \\
\hline
\end{tabular}

Table 2: Comparison between postoperative hemorrhage in patients.

\begin{tabular}{|c|c|c|}
\hline \multirow{2}{*}{ Parameter } & $\begin{array}{c}\text { Coblation (507 } \\
\text { Patient) }\end{array}$ & $\begin{array}{c}\text { Traditional (497 } \\
\text { Patient) }\end{array}$ \\
\cline { 2 - 3 } & \multicolumn{2}{|c|}{ Percent } \\
\hline Primary hemorrhage & $0.2 \%$ & $0.8 \%$ \\
\hline $\begin{array}{c}\text { Secondary } \\
\text { hemorrhage }\end{array}$ & $1.2 \%$ & $0.2 \%$ \\
\hline
\end{tabular}

\section{Discussion}

Tonsillectomy is one of the most common operations performed in otolaryngology worldwide. Coblation tonsillectomy is a recently introduced dissecting technique with few reports in the literature. In this study we compared two techniques of tonsillectomy, the coblation and traditional. Some significant differences were shown between outcomes of these two methods. Tonsillectomy with steel forceps (as traditional) consumes longer time than coblation tonsillectomy does as a slower dissection [13]. Several studies were done to demonstrate the advantages and disadvantages of coblation tonsillectomy. This study was done to compare between the commonly used dissection tonsillectomy and the relatively new coblation method. Comparison included most of the surgical aspects, the operative and postoperative ones.

As regard the operative time, tonsillectomy is considered to be one of the most common surgical procedures performed in the field of otolaryngology. In fairly experienced hands, the conventional (cold) tonsillectomy takes considerably short operative time. In our study, the time was measured from insertion till removal of mouth gag. The operation time was longer with traditional method than in the coblation method. The mean score for the operative time was $30.66 \pm 8.66$ minutes in the traditional group as compared to $10.63 \pm 2.45$ minutes in the coblation group. The mean operation time was thus significantly less for coblation group $(\mathrm{p}<0.000)$.

We agree with Paramasivan VK et al. [14] who conducted a prospective and comparative study in Madras ENT Research Foundation, Chennai over a period of 6 months on 50 children. This study reported that operative time was more in dissection method compared to coblation technique. Also we agree with
Behrouz Barati et al (2012) who conducted a study on 94 patients 47 in each group and they reported that the mean operation time was $31 \pm 5.4$ minutes ( ranging from 20 - 45 minutes) in the traditional tonsillectomy group and $27.3 \pm 4.8$ minutes ( ranging from 18-42 minutes) in the coblation group. The mean operation time was significantly less in the coblation group $(\mathrm{p}<0.001)$.

Furthermore we agree with Rosdan S et al. [15] who conducted a study on 34 patients who underwent tonsillectomy. Results showed that the intraoperative time was significantly shorter $(\mathrm{p}<0.001)$ in coblation tonsillectomy as compared to cold dissection tonsillectomy. On the other hand, we disagree with T.S Anand and George Payal (2011) who performed a study on 60 patients. This study reported that the mean operation time was 11 minutes and that for the coblation method was $15 \mathrm{~min}$. Thus it took an average of four minutes longer to perform the coblation procedure compared to the conventional technique, but this difference did not reach statistical significance $(\mathrm{P}>$ $0.05)$.

As regard the intra-operative blood loss, some studies showed results in favor of coblation tonsillectomy while other studies reported that there is no significant difference in the intra-operative blood loss between the two methods. In our study, the estimated loss was $65.06 \pm 8.73 \mathrm{ml}$ in the coblation group as compared to $174.31 \pm 43.98 \mathrm{ml}$ in the conventional. This reflects a considerable difference between the two methods in this particular aspect. We agree with Temple and Timms [16] who stated that the average blood loss is less with coblation. Also we agree with O'Leary and Vorrath (2005) reported higher blood loss in the traditional method than that obtained with coblation method. But we disagree with Hall et al. [17] and Chang KW [18] that showed no difference in blood loss between the two methods.

As regard the postoperative haemorrhage we disagree with Belloso et al. [19] who compared the complication rates in coblation versus conventional tonsillectomy methods. In their study, coblation tonsillectomy was associated with a lesser incidence of delayed hemorrhage, more significantly in the pediatric population. And disagree with Behrouz Barati et al. (2012) who reported that postoperative secondary hemorrhage rate (1 versus 5) was slightly higher in traditional group than the coblation group. But we agree with Noon and Hargreaves [20,21] who conducted a clinical study on 36 adults who underwent coblation tonsillectomy, and found a significant increase in the rate of the secondary haemorrhage $(22 \%$ as compared to $3.4 \%$ in the dissection method). They concluded that the problem is more significant when it comes to adults. The incidence of post tonsillectomy hemorrhage apparently increases among adults operated upon using the coblation technique.

Also we agree with Van der Meulen and Lowe [22] who reported higher incidence of postoperative hemorrhage when coblation is used. They confirmed need for appropriate caution 
and proper training on the coblation method. Furthermore we agree with Windfuhr, Deck and Remmert [4] who reported higher incidence of post tonsillectomy hemorrhage in adults and children who underwent coblation tonsillectomy. Secondary hemorrhage was $7.9 \%$ with coblation versus $0.8 \%$ with the conventional method. They stated that the conventional tonsillectomy remain to be the method of choice. On the other hand Divi and Benninger [23] started their experience with coblation tonsillectomy at their institution in Detroit, USA. They found no significant difference in postoperative bleeding in both methods. However, they stated that a learning curve could be identified when using postoperative bleeding as an outcome measure for coblation tonsillectomy.

In order to evaluate the return to normal activities, the patients were asked in the postoperative days if they would be able to return to work. Another factor which assessed the clinical recovery was retrieving normal diet. The results were significantly different, mean return to normal diet period was significantly shorter in the coblation group (5.00 \pm 1.41 vs. $9.95 \pm 1.98$ days $)(p<0.000)$, return to normal behavior was earlier in the coblation group $(10.30 \pm 2.80$ vs. $13.59 \pm 3.74$ days $)$ $(\mathrm{p}<0.000)$. In our study, the reduction of intraoperative blood loss and operation time in coblation tonsillectomy was obvious and early return to normal diet and activities were clinically and statistically significant. Furthermore, it was revealed that postoperative primary hemorrhage rate was higher in traditional group. However, secondary hemorrhage rate was higher in coblation group than traditional group [24,25].

\section{Conclusion}

The new technique using coblation for tonsillectomy offers significant advantages in the operation time and intra operative blood loss compared with dissection tonsillectomy. Coblation is associated with early return to daily activities and normal diet. Also, coblation tonsillectomy is associated with a higher incidence of secondary hemorrhage. Therefore, we believe that the traditional method of tonsillectomy remain to be the method of choice.

\section{References}

1. Lowe D, van der Meulen J, Cromwell D, Lewsey J, Copley L, et al. (2007) Key messages from the National Prospective Tonsillectomy Audit Laryngoscope 117(4): 717-724.

2. Pinder DK, Wilson H, Hilton MP (2011) Dissection versus diathermy for tonsillectomy. Cochrane Database Syst Rev (3): CD002211.

3. Raut V, Bhat N, Kinsella J, Toner JG, Sinnathuray AR, et al. (2001) Bipolar scissors versus cold dissection tonsillectomy: a prospective, randomized, multi-unit study. Laryngoscope 111(12): 2178-2182.

4. Windfuhr JP, Deck JC, Rommert S (2005) Hemorrhage following coblation tonsillectomy. Ann Otol Rhinol Laryngol 114(10): 749-756.

5. Lee KC, Bent JP, Dolitsky JN, Hinchcliffe AM, Mansfield EL, et al. (2004) Surgical advances in tonsillectomy: report of a roundtable discussion. Ear Nose Throat J 83(8): 4-13.
6. Burton MJ, Doree C (2007) Coblation versus other surgical techniques for tonsillectomy. Cochrane Database Syst Rev 3: CD004619.

7. Polites N, Joniau S, Wabnitz D, Fassina R, Smythe C, et al. (2006) Postoperative pain following coblation tonsillectomy: randomized clinical trial. ANZ J Surg 76(4): 226-229.

8. Temple R, Timms M (2001) Pediatric coblation tonsillectomy. Int J Ped Otorhinolaryngol 61: 195-198.

9. Temple RH, Timms MS (2001) Paediatric coblation tonsillectomy. Int J Pediatr Otorhinolaryngol 61(3):195-198.

10. Timms MS, Temple RH (2002) Coblation tonsillectomy: a double blind randomized controlled study. J Laryngol Otol 116(6): 450-452.

11. Arya A, Donne AJ, Nigam A (2003) Double-blind randomized controlled study of coblation tonsillotomy versus coblation tonsillectomy on postoperative pain. Clin Otolaryngol Allied Sci 28(6): 503-506.

12. Philpott CM, Wild DC, Mehta D, Daniel M, Banerjee AR (2005) A doubleblinded randomized controlled trial of coblation versus conventional dissection tonsillectomy on postoperative symptoms. Clin Otolaryngol 30(2): 143-148.

13. Pizzuto MP, Brodsky L, Duffy L, Gendler J, Nauenberg E (2000) A comparison of microbipolar cautery dissection to hot knife and cold knife cautery tonsillectomy. Int J Pediatr Otorhinolaryngol 52(3): 239246.

14. Paramasivan VK, Arumugam SV, Kameswaran M (2012) Randomized comparative study of adenotonsillectomy by conventional and coblation method for children with obstructive sleep apnea. Int J Pediatr Otorhinolaryngol 76(6): 816-821.

15. Rosdan S, Izny Hafiz, Mod Khairi MD (2013) Coblation tonsillectomy versus dissection tonsillectomy: a comparison of intraoperative time, intraoperative blood loss and post-operative pain. Med J Malaysia 69(2): 74-78.

16. Timms MS, Temple RH (2002) Coblation tonsillectomy: a double blind randomized controlled study. J Laryngol Otol 116(6): 450-452.

17. Hall DJ, Littlefield PD, Birkmire-Peters DP, Holtel MR (2004) Radiofrequency ablation versus electrocautery in tonsillectomy. Otolaryngol. Head Neck Surg 130: 300-305.

18. Chang KW (2005) Randomized controlled trial of coblation versus electrocautery tonsillectomy. Otolaryngol Head Neck Surg 132(2): 273- 280.

19. Belloso A, Chidambaram A, Morar P, Timms M (2003) Coblation tonsillectomy versus dissection tonsillectomy: post- operative hemorrhage. Laryngoscope 113(11): 2010-2013.

20. Noon AP, Hargreaves S. (2003) Increased post-operative haemorrhage seen in adult coblation tonsillectomy. Laryngol Otol 117(9): 704-706.

21. Noon AP, Hargreaves S (2003) Increased postoperative haemorrhage seen in adult coblation tonsillectomy. J Laryngol Otol 117(9): 704-706.

22.Van der Meulen J, Lowe D (2004) Coblation tonsillectomy as a risk factor for post operative haemorrhage. National Prospective Tonsillectomy Audit. Lance 364(9435): 697-702.

23. Divi Venu, Benninger Michael (2005) Post-operative Tonsillectomy Bleeding: Coblation Versus non coblation. Laryngoscope 115(1): 3133.

24. Wiatrak BJ, Willging JP (2002) Harmonic scalpel for tonsillectomy. Laryngoscope 112(8 Pt 2 Suppl 100): 14-16.

25. O’Leary S, Vorrath J (2005) Post-operative bleeding after diathermy and dissection tonsillectomy. Laryngoscope 115(4): 591-594. 

(i) Commons Attribution 4.0 License

DOI:_10.19080/GJ0.2017.06.555690
Your next submission with Juniper Publishers will reach you the below assets

- Quality Editorial service

- Swift Peer Review

- Reprints availability

- E-prints Service

- Manuscript Podcast for convenient understanding

- Global attainment for your research

- Manuscript accessibility in different formats

( Pdf, E-pub, Full Text, Audio)

- Unceasing customer service

Track the below URL for one-step submission https://juniperpublishers.com/online-submission.php 